\title{
Saberes pedagógicos para la enseñanza infantil desde la perspectiva de personas educadoras de infantes
}

\begin{abstract}
Pedagogical knowledge for early childhood education from the perspective of early childhood educators
\end{abstract}

\author{
Volumen 22, Número 1 \\ Enero - Abril \\ pp. 1-33
}

\author{
Carolina Flores Lueg \\ Tania Alvarado Retamal \\ Tannia Belén Gutiérrez Oyarce \\ Sandra Patricia Medel Lillo
}

Citar este documento según modelo APA

Flores Lueg, Carolina., Alvarado Retamal, Tania., Gutiérrez Oyarce, Tannia Belén., y Medel Lillo, Sandra Patricia. (2022). Saberes pedagógicos para la enseñanza infantil desde la perspectiva de personas educadoras de infantes. Revista Actualidades Investigativas en Educación, 22(1), 1-33. Doi. https://doi.org/10.15517/aie.v22i1.47433 


\title{
Saberes pedagógicos para la enseñanza infantil desde la perspectiva de personas educadoras de infantes
}

Pedagogical knowledge for early childhood education from the perspective of early childhood educators

\author{
Carolina Flores Lueg ${ }^{1}$ \\ Tania Alvarado Retamal ${ }^{2}$ \\ Tannia Belén Gutiérrez Oyarce ${ }^{3}$ \\ Sandra Patricia Medel Lillo 4
}

\begin{abstract}
Resumen: En este artículo se presentan los resultados de un estudio sobre las significaciones que las educadoras de infantes les otorgan a los saberes profesionales y pedagógicos que sustentan su labor docente y le dan sentido a sus prácticas de enseñanza. La investigación se situó desde un paradigma interpretativo, con una metodología cualitativa y el método fenomenológico hermenéutico. Fue desarrollada en el año 2020 con la participación de siete educadoras incluidas intencionalmente según criterios previamente definidos y su disponibilidad, quienes desempeñan su labor en establecimientos escolares ubicados en la Región de Ñuble, Chile. Como técnica de producción de información se empleó la entrevista semiestructurada, y el análisis de los datos se realizó por medio de un proceso de categorización mixta (deductiva e inductiva). Desde la perspectiva deductiva, la categoría central para el análisis fue "saberes profesionales" $y$, desde la perspectiva inductiva, "saberes experienciales adquiridos sobre la enseñanza" y "procesos de reflexión docente". Se consideró la triangulación intersujetos como procedimiento para garantizar la credibilidad de la información. Los principales resultados evidencian que, para las educadoras, los saberes pedagógicos representan el cimiento de su identidad profesional, cuya dimensión experiencial se constituye en el principal marco referencial sobre el cual resuelven emocional e intuitivamente las situaciones de enseñanza.
\end{abstract}

Palabras clave: saberes docentes, educación infantil, práctica pedagógica, enseñanza.

Abstract: This article presents the results of a study on the meanings that early childhood educators give to the professional and pedagogical knowledge that sustains their teaching work and gives meaning to their teaching practices. The research it situated from an interpretive paradigm, with a qualitative methodology and the hermeneutical phenomenological method. It was developed in 2020 with the participation of seven educators intentionally included according to defined criteria and their availability, who work in schools located in the Region de Nuble, Chile. The production technique of information was the semi-structured interview and the data analysis it carried out through a mixed categorization process (deductive and inductive). From the deductive perspective, the central category for the analysis was professional knowledge, and from the inductive perspective, experiential knowledge acquired about teaching and teacher reflection processes. It was considered inter-subjects triangulation as a procedure to validate the information. The main results show that for educators, pedagogical knowledge represents the foundation of their professional identity, whose experiential dimension constitutes the main referential framework on which they emotionally and intuitively resolve teaching situations.

Keywords: teaching knowledge, early childhood education, pedagogical practice, teaching.

\footnotetext{
${ }^{1}$ Académica de la Universidad del Bío-Bío, en el Departamento de Ciencias de la Educación, Concepción, Bío Bío, Chile. Dirección electrónica: cflores@ubiobio.cl Orcid https://orcid.org/0000-0001-5219-0617

2 Educadora de Párvulos, Universidad del Bío-Bío, Concepción, Bío Bío, Chile. Dirección electrónica: alvaradotania1997@gmail.com Orcid https://orcid.org/0000-0001-7522-2343

${ }^{3}$ Educadora de Párvulos, Universidad del Bío-Bío, Concepción, Bío Bío, Chile. Dirección electrónica: taniagutierrezoyarce@gmail.com Orcid https://orcid.org/0000-0001-5505-3917

${ }^{4}$ Educadora de Párvulos, Universidad del Bío-Bío, Concepción, Bío Bío, Chile. Dirección electrónica: lillosandrapatricia@gmail.com Orcid https://orcid.org/0000-0002-6898-6342
}

Artículo recibido: 16 de junio, 2021

Enviado a corrección: 20 de setiembre, 2021

Aprobado: 25 de octubre, 2021

Los contenidos de este artículo están bajo una licencia Creative Commons 


\section{Introducción}

La educación infantil o educación parvularia desde hace algún tiempo se ha constituido en uno de los focos de atención para la implementación de diferentes políticas públicas tendientes al mejoramiento de los procesos formativos de niños y niñas menores de seis años ${ }^{5}$ tanto a nivel internacional como chileno (Bravo y Morales, 2012; Cortázar y Vielma, 2017; Rolla, Leal y Torres, 2011). Estas políticas tienen su sustento en los aportes teóricos y empíricos emanados desde diversos ámbitos disciplinarios, entre ellos, la economía, la psicología, la pedagogía y las neurociencias. Particularmente, las investigaciones generadas desde estas últimas son concluyentes en destacar la importancia de los primeros años de vida para el desarrollo posterior de un ser humano (Ramírez-Abraham, Patiño-Mora y GamboaVásquez, 2014; Román y Poenitz, 2018; Zabalza, 2018). Si bien, algunos estudios, desde el ámbito educativo, evidencian que la asistencia de infantes a los centros escolares tiene incidencia en el mejoramiento de los resultados en los aprendizajes en los niveles educativos siguientes (Aguilar y Tansani, 2012; Banco Mundial, 2011; Cortázar y Vielma, 2017) se concuerda con Belsky (2005) cuando señala que el impacto de la educación parvularia solo tiene lugar en la medida en que los y las infantes reciban una enseñanza de calidad, de lo contrario, incluso, puede llegar a ser perjudicial para su desarrollo socioemocional y cognitivo. Esta condición estaría determinada por la idoneidad del desempeño profesional de educadores y educadoras, las características que presentan sus prácticas docentes y el dominio de un saber especializado que les permita fundamentar las decisiones que emprenden sobre el diseño, implementación y evaluación de un proceso educativo organizado (FloresLueg, Gajardo-Rodríguez y Navarrete-Troncoso, 2016; Moreno Vera y de la Herrán Gascón, 2017).

Algunos estudios focalizados en indagar acerca de los saberes docentes que poseen educadoras de infantes en el contexto chileno evidencian ciertas debilidades en el ejercicio profesional originadas por factores de naturaleza individual y contextual, teórica y práctica, las que, en su conjunto, afectan la implementación exitosa del saber docente que debería caracterizar la profesión (Lería, Salgado y Sasso, 2018). En esta línea, Morales, Quilaqueo y Uribe (2010) concluyen que las educadoras presentan desconocimiento de algunos aportes

\footnotetext{
${ }^{5}$ La Ley N²0.370, Ley General de Educación en su Artículo 18 establece que la Educación Parvularia es el nivel educativo que atiende integralmente a niños desde su nacimiento hasta su ingreso a la educación básica, sin constituir antecedente obligatorio para ésta. Su propósito es favorecer de manera sistemática, oportuna y pertinente el desarrollo integral y aprendizajes relevantes y significativos en los párvulos, de acuerdo a las bases curriculares que se determinen en conformidad a esta ley, apoyando a la familia en su rol insustituible de primera educadora.
} 
teóricos que se consideran relevantes dentro de la pedagogía actual para la infancia y, en relación con ello, Moreno Vera y de la Herrán Gascón (2017) demuestran que estas profesionales poseen un nivel de conocimientos disciplinares y pedagógicos extremadamente bajo, al destacar, además, que no tienen consciencia de esta debilidad.

Otras investigaciones centradas en indagar sobre los procesos reflexivos que implementan educadoras en su labor docente son concluyentes en señalar que estos se orientan fundamentalmente desde una perspectiva técnica normativa y técnica funcional, pero que escasamente logran avanzar hacia procesos reflexivos de tipo práctico relacional (Cortés Véliz, 2014). Esta situación conlleva a evidenciar una ausencia de argumentos para mantener posiciones epistemológicas y pedagógicas que les permitan resguardar los sentidos de la educación infantil.

Se desprende así que existirían ciertas lasitudes en el desempeño profesional de estas maestras asociadas al dominio de conocimientos teóricos-conceptuales y prácticos, así como también, respecto de los procesos reflexivos que implementan. Estas debilidades tendrían implicancias en la movilización de aquellos saberes pedagógicos indispensables para un óptimo desempeño y, en consecuencia, para el logro en la calidad de la educación parvularia, pues esta situación tensionaría las posibilidades reales para el ejercicio de su autonomía y desarrollo profesional, más aún, teniendo en consideración que desde el escenario político, social y educativo chileno, recientemente se ha comenzado a legitimar la función pedagógica que se desarrolla en una etapa tan sensible en el ser humano, como lo es aquella correspondiente a sus primeros años de vida.

A partir de lo expuesto y con el interés de aportar al conocimiento sobre los saberes profesionales que poseen educadoras de infantes, esta investigación se centró en identificar las significaciones que les otorgan a los saberes teóricos y prácticos que fundamentan su labor docente, junto con determinar los procesos reflexivos que señalan implementar en sus prácticas. Este propósito se plantea bajo el entendido de que las significaciones se refieren a las comprensiones e importancia proporcionada a ambos tipos de saberes, cuyo contraste por medio de acciones reflexivas comprometidas favorecen la elaboración del saber pedagógico, ese saber que actúa como marco epistémico que da sustento y sentido a la enseñanza de los niños y las niñas. 


\section{Fundamentación teórica}

\subsection{Aproximación conceptual a la noción de "saberes docentes"}

El saber, como categoría, ha sido examinado desde distintas perspectivas teóricas, epistemológicas y filosóficas (Charlot, 2010). Para Altet (2005), dicho saber corresponde a una construcción que surge desde la interacción entre "conocimiento e información, entre sujeto y entorno, dentro y a través de la mediación" (p.42). Esta autora señala que la información es externa al sujeto y al orden social; mientras que el conocimiento es integrado por el sujeto y es de carácter personal. Por consiguiente, la noción de saber corresponde a lo que un sujeto ha adquirido a partir del conocimiento que va construyendo, deconstruyendo y reconstruyendo en la práctica (Pedemonte, 2009; Porta y Cometta, 2017), y que es "elaborado gracias al estudio o la experiencia" (Beillerot, 1998, p.16)

Atendiendo a lo anterior, aludir a la noción de "saberes docentes" implica situarse desde la pluralidad, pues responde a un marco epistémico conformado por múltiples tipos de saberes que convergen en el quehacer del profesorado, saberes que se movilizan y emplean en la práctica cotidiana para resolver problemas y dar sentido a las "situaciones de trabajo que les son propias" (Tardif, 2010, p. 45). Siguiendo a Tardif (2010), este encuadre involucra los siguientes tipos de saberes:

- Profesionales: aquellos que son seleccionados y transmitidos a través de los programas de estudio que son impartidos por las instituciones de formación del profesorado (Escuelas de Magisterio o Facultades de Ciencias de la Educación), tanto a nivel de la formación inicial como continua. Estos saberes se enmarcan en el conocimiento científico que es generado desde las ciencias humanas y ciencias de la educación, y se transforman en un tipo de conocimiento destinado a la formación científica y erudita del profesorado. Desde las instituciones formadoras, además, se procura que este tipo de saber sea incorporado a la práctica docente.

- Disciplinares: corresponden a los diversos campos del conocimiento en forma de disciplinas que surgen de la tradición cultural y de los grupos sociales productores de saberes, que son transmitidos en los cursos y departamentos universitarios.

- Curriculares: referidos a los discursos, objetivos, contenidos y métodos a partir de los cuales la institución escolar categoriza y presenta los saberes sociales que ella misma define y selecciona como modelo de la cultura erudita. Se presentan en forma de programas escolares (objetivos, contenidos, métodos) que el profesorado debe aprender a aplicar. 
- Experienciales o prácticos: saberes específicos que el profesorado desarrolla a partir de la práctica de su profesión, vale decir, "brotan de la experiencia individual y colectiva en forma de hábitos y de habilidades, de saber hacer y de saber ser" (Tardif, 2010, p. 30). Se constituyen en saberes que son validados en la acción y responden a un conjunto de representaciones que sirven de base al personal docente para orientar su profesión y darle sentido a su práctica cotidiana en todas sus dimensiones.

- Pedagógicos: doctrinas o concepciones provenientes de reflexiones sobre la práctica educativa, en el sentido amplio del término, reflexiones racionales y normativas que conducen a sistemas más o menos coherentes de representación y de orientación de la actividad educativa (Tardif, 2010, pp. 29-30).

\subsection{Saber pedagógico del docente como sustento para la enseñanza}

Hacer referencia a saber pedagógico del docente no está exento de dificultades, pues en la actualidad se encuentran diversas perspectivas que han intentado teorizar y establecer un marco conceptual sobre qué es este saber, qué tipo de saberes debe poseer el profesorado para el ejercicio de su profesión, cómo se adquiere este saber, entre otras cuestiones. Lo anterior ha generado una extensa y diversa discusión sobre su comprensión y descripción (Echeverría, 2010). No obstante, se concuerda con Herrera y Martínez (2018), quienes sostienen que el saber pedagógico contiene una dimensión teórica representada en las doctrinas pedagógicas ajustadas a la ideología de la "Escuela Nueva", junto con una dimensión práctica centrada en la enseñanza y en los discursos asociados a ella (Tardif, 2010).

El saber pedagógico, desde su dimensión práctica se entiende como un "saber en uso", un saber inherente a la acción, que está conformado por representaciones a partir de las cuales el profesorado orienta su labor (Tardif, 2010). En palabras de Sánchez-Amaya y González-Melo (2016),

sería todo aquello que se puede decir, que se puede enunciar, acerca de la pedagogía o de las prácticas pedagógicas, que un sujeto —el maestro- pone en funcionamiento en el acto de enseñar, esto es, el fundamento de su práctica. (p. 247)

Si bien, el saber pedagógico refleja un tipo de conocimiento práctico de origen experiencial, su distinción radica en que está contextualizado y es re/construido a partir de la reflexión sistemática en y sobre la práctica de enseñanza (Vezub, 2016). Para Messina (2008), este saber "forma parte de un mundo de sentido donde es central mirar la experiencia y 
reflexionarla para su transformación" (p. 5). Por su parte, Echeverría (2010) señala que la experiencia no solo se va asimilando desde el intelecto, sino también desde los sentidos. Por tanto, se presenta derivada de una dimensión cognitiva y afectiva/sensitiva. A su vez, se constituye en un tipo de saber que adopta una dimensión histórica, en cuanto forma parte del proceso histórico local, de la relación cotidiana entre la persona docente y estudiantes (Mercado, 2018). Se asume de este modo como una construcción social.

En consecuencia, el saber pedagógico del profesorado emerge desde la pregunta sobre el "sentido de la experiencia vivida" (Contreras, 2011, p. 61), pero al amparo de aquellos procesos reflexivos que le permiten dialogar con una situación particular de enseñanza (Ruffinelli, 2017; Suescun Guerrero y León Salazar, 2018). Si bien, se manifiesta como un tipo de saber situado al margen del conocimiento generalizable o abstracto propio del ámbito de la ciencia y de las perspectivas positivistas (Hizmeri et al., 2020), se visualiza como el sustento que permite al docente darle sentido a su labor pedagógica.

Finalmente, concordamos con Merellano-Navarro, Almonacid-Fierro y Muñoz-Uyarce (2019) cuando señalan que la construcción del saber pedagógico requiere de una práctica reflexiva comprometida, con sentido e intencionalidad, que permita al profesorado ser capaz de implementar su enseñanza bajo la noción de praxis; es decir, una noción sostenida a partir de un diálogo permanente que transite desde la práctica hacia la teoría y desde la teoría hacia la práctica, para con ello generar una amalgama de conocimientos cuya emergencia se genera a partir del diálogo entre ambos dominios.

\subsection{Reflexión docente como base para el desarrollo profesional}

La reflexión docente se ha constituido en una dimensión del desarrollo profesional orientada a que el profesorado comprenda el trabajo pedagógico desde una acción reflexiva, en tanto se concibe como un proceso vital que permite desarrollar la capacidad para analizar su propia enseñanza con el propósito de mejorarla (Messina, 2008; Molina, 2008). Por consiguiente, en los discursos en y sobre la pedagogía se promueve la figura del profesorado como un profesional reflexivo (Schön, 1998), como una persona que posee la capacidad para analizar y valorar la variedad de situaciones, contextos, conocimientos y saberes que son movilizados al momento de desarrollar una acción educativa frente a un grupo de estudiantes.

Dentro de la noción de profesional reflexivo propuesta por Schön (1998) se evidencian dos niveles o ámbitos de la reflexión: i) "reflexión en la acción", donde la acción docente involucraría el desarrollo de relatos descriptivos o apreciaciones cualitativas acerca de los 
procesos de enseñanza, convirtiendo al profesorado en investigador en el contexto práctico; ii) "reflexión sobre la práctica", vinculante con procesos reflexivos orientados a la resignificación de creencias del profesorado para transformar las teorías implícitas en discursos explícitos que le dan sustento a la enseñanza. Por su parte, Molina (2008), teniendo en consideración la racionalidad que subyace a la práctica reflexiva, avanza en la distinción de los siguientes tres niveles: i) "reflexión técnica", que describe acciones y procedimientos desarrollados en la implementación pedagógica; ii) "reflexión práctica”, que introduce acciones deliberativas vinculadas a la planificación y didáctica de la enseñanza del contenido disciplinar, junto con su adecuación a la realidad áulica; iii) "reflexión crítica", que involucra análisis contextuales y sus complejidades, junto con consideraciones ético-políticas de la propia práctica desarrollada.

Finalmente, si se tiene en consideración que la reflexión docente es entendida como el modo de conexión entre el pensamiento y la acción a partir de la cual emerge un nuevo saber capaz de cambiar el repertorio del profesorado, de generar aprendizaje profesional y mejorar con ello su práctica pedagógica (Ruffinelli, 2017), concordamos con Vezub (2016) cuando señala que la capacidad para reflexionar sobre las prácticas, las actitudes de indagación y de cuestionamiento que permiten la mejora permanente de la enseñanza "se originan en la formación inicial, por lo que se espera que las instituciones sienten las bases del futuro desarrollo, trasmitiendo la provisionalidad del conocimiento y el imperativo de la actualización" (p. 4). Por lo tanto, la reflexión docente responde a una práctica deliberativa que requiere ser intencionada y promovida desde la formación inicial docente para continuar implementándose a lo largo del desarrollo profesional.

\section{Metodología}

\subsection{Enfoque}

Este estudio se sitúa desde un paradigma comprensivo-interpretativo y una metodología cualitativa, porque se busca lograr una aproximación a la realidad construida por las personas participantes desde sus comprensiones-significaciones (Flick, 2012). Se empleó como método la Fenomenología Hermenéutica (van Manen, 2003), dado que el interés investigativo principal se centró en lograr la compresión del significado otorgado por las participantes a sus saberes pedagógicos y a la importancia que estos tienen dentro su contexto de aplicación (AyalaCarabajo, 2018). El empleo de ese método se justifica por su pertinencia al objeto de estudio, por cuanto el saber pedagógico se caracteriza por ser situado, subjetivo y emerger desde las 
prácticas de enseñanza que tienen lugar en el mundo del aula. Por consiguiente, el alcance de la investigación es del tipo descriptivo-interpretativo.

\subsection{Participantes en el estudio}

Participaron siete educadoras de infantes seleccionadas a partir de un muestreo intencional (Ruiz, 2012), quienes fueron incluidas teniendo en consideración los siguientes criterios definidos en forma interna a la investigación: ejercicio de su labor educativa al menos cuatro años; desempeño en establecimientos escolares públicos y subvencionados ubicados en la ciudad de Chillán, Región de Ñuble, situada en el centro sur de Chile; haber ejercido la función de educadora guía de estudiantes en práctica profesional (ver Tabla 1).

\section{Tabla 1}

Caracterización de la muestra del personal docente, Región de Ñuble-Chile, 2020 Criterios de inclusión

\begin{tabular}{ccccc}
\hline Ejercicio de la labor educativa & \multicolumn{2}{c}{$\begin{array}{c}\text { Tipo de administración del } \\
\text { establecimiento }\end{array}$} & $\begin{array}{c}\text { Haberse desempeñado } \\
\text { como Educadora Guía de } \\
\text { Práctica }\end{array}$ \\
\hline $\begin{array}{c}\text { Entre } 4 \text { y } 10 \\
\text { años }\end{array}$ & $\begin{array}{c}\text { Entre } 11 \text { y } \\
20 \text { años }\end{array}$ & Públicos & $\begin{array}{c}\text { Subvencionados } \\
\text { o concertados }\end{array}$ & \begin{tabular}{c} 
conn \\
\hline 3
\end{tabular} \\
\hline & 4 & 4 & 3 & 7 \\
\hline & Fuente: Elaboración propia (2021)
\end{tabular}

Fuente: Elaboración propia (2021)

Desde el punto de vista ético, se respetó la voluntad de las participantes para participar en el estudio, lo que fue expresado previamente por medio de la firma de un consentimiento informado. En este documento se explicitó el propósito de la investigación, el compromiso de las personas investigadoras y el detalle de aspectos concernientes a la participación. Del mismo modo, en la presentación de los resultados se atiende al resguardo de la identidad al considerar la siguiente simbología: Educadora 1 (E1), Educadora 2 (E2), Educadora 3 (E3), Educadora 4 (E4), Educadora 5 (E5), Educadora 6 (E6) y Educadora 7(E7).

\subsection{Técnicas de recolección de información}

Se empleó como técnica de producción de información la entrevista semiestructurada, entendida como una forma específica de conversación en la que se genera conocimiento mediante la interacción entre una persona investigadora y una entrevistada, que admite la "apertura a los cambios de secuencia y las formas de las preguntas, para profundizar en las respuestas que los entrevistados dan y las historias que cuentan" (Kvale, 2011, p. 93). En su estructuración, se comenzó con un guión de preguntas propuesto con el fin de organizar el 
curso de la entrevista y ajustarlo a la indagación sobre el saber profesional de las educadoras, saberes pedagógicos y experienciales, además de sus comprensiones sobre los procesos reflexivos que implementan, pero durante su desarrollo se fueron incorporando nuevas preguntas centradas en lograr una aproximación al saber pedagógico construido por ellas a lo largo de su experiencia profesional. Cabe destacar que este guion inicial, de carácter orientativo, fue sometido a una validación de contenido mediante el juicio de tres personas expertas seleccionadas con base en los siguientes criterios: i) todas debían contar con postgrado en pedagogía o educación, ii) una de ellas debía evidenciar trayectoria académica en el ámbito temático (saber pedagógico), iii) otra debía demostrar experiencia profesional y académica en la educación parvularia, iv) otra con experticia en el desarrollo de la investigación cualitativa. Las observaciones y sugerencias recogidas en este proceso permitieron optimizar el esquema de preguntas propuesto en forma previa a su aplicación.

La entrevista fue administrada a cada una de las participantes en forma virtual durante el año 2020, a través de la plataforma Zoom debido a la condición de pandemia generada por la enfermedad COVID-19. Cada uno de los encuentros tuvo una duración aproximada de cincuenta minutos, la conversación fue grabada previa autorización de cada persona entrevistada y posteriormente transcrita en forma literal.

\subsection{Procesamiento de análisis}

El análisis de la información se realizó por medio de un proceso de categorización mixto que contempló un procedimiento deductivo y otro inductivo (Bisquerra, 2004). Desde la dimensión deductiva se consideró como categoría central "saber profesional" (Tardif, 2010), que fue operacionalizada en las siguientes subcategorías: saber curricular, saber didáctico, saber evaluativo y saber sobre teorías del aprendizaje; todas ellas situadas desde el dominio de conocimientos teóricos. Desde la dimensión inductiva emergieron las siguientes categorías: "saberes experienciales adquiridos sobre la enseñanza" y "procesos de reflexión docente". Las respuestas de las entrevistas se analizaron a partir de la condensación de significado de base fenomenológica, procedimiento entendido como el "resumen de los significados expresados por los entrevistados en formulaciones más breves" (Kvale, 2011, p.140) y la interpretación de dichos significados. En términos operativos, este proceso analítico consideró los siguientes cinco pasos propuestos por Kvale (2011): i) lectura entera de cada entrevista; ii) determinación de unidades de significado natural de los textos, tal como lo expresan los sujetos; iii) formulación del tema que domina una unidad de significado natural; iv) interrogación de las 
unidades de análisis en función del propósito del estudio; v) enlace de los temas no redundantes en una declaración descriptiva.

Para resguardar la calidad de los datos analizados, se empleó como procedimiento la triangulación intersujetos, buscando convergencias y divergencias de significaciones expresadas en los discursos. Todo el proceso analítico fue realizado por las investigadoras y estuvo apoyado por el software Atlas.ti v. 8.

\section{Resultados}

En este apartado se comienza presentando los principales resultados referidos a la categoría de naturaleza deductiva: "saber profesional", definida como las comprensiones teóricas que poseen las educadoras participantes sobre el currículum, la didáctica, la evaluación y las teorías del aprendizaje que les dan sustento a sus prácticas como enseñantes. Seguidamente, se exponen los resultados vinculados a las categorías de base inductiva: saberes experienciales que han ido adquiriendo sobre la enseñanza de infantes en el ejercicio de la profesión y procesos de reflexión docente que las participantes señalan implementar dentro de su labor pedagógica. Esta organización ha sido pensada atendiendo al siguiente orden: i) saberes de naturaleza teórica, ii) saberes de naturaleza práctica y iii) reflexión docente, entendiéndose esta como aquella acción deliberativa que permite vincular dialécticamente los saberes teóricos y prácticos como cualidad inherente al saber pedagógico. Si bien, los resultados de cada categoría se muestran operativamente en forma diferenciada, estos se enlazan simultáneamente con los códigos asignados a las unidades de significados que fueron emergiendo en el análisis (Ver Figura 1). 
Figura 1

Red de códigos derivada del análisis de la información de las entrevistas aplicadas a siete (7) participantes, establecimientos públicos y subvencionados ubicados en la Región de Ñuble, Chile, año 2020

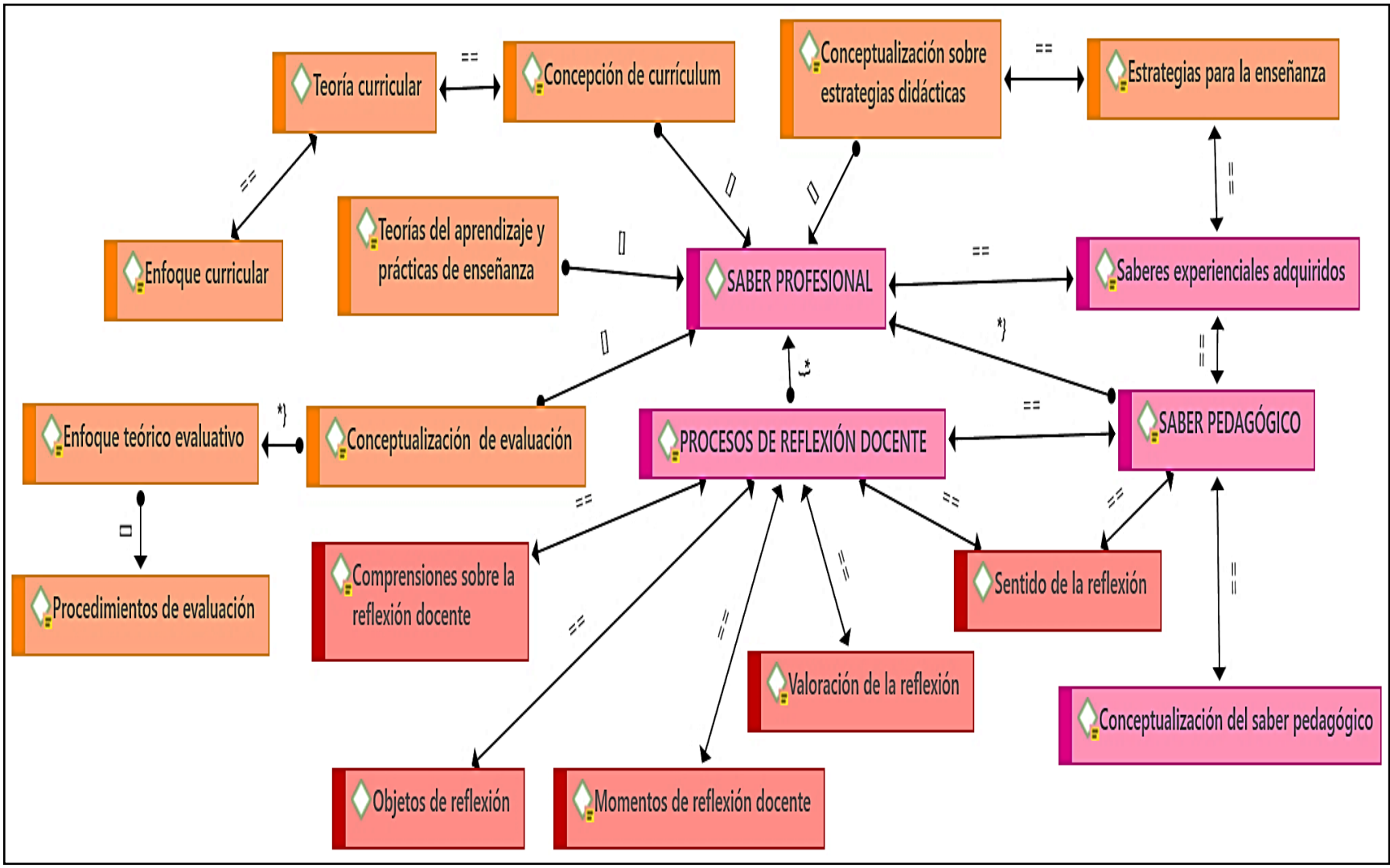

Fuente: Elaboración propia a partir del software Atlas.ti v. 8

\subsection{Saber profesional que sustenta la práctica de enseñanza}

\subsubsection{Saberes curriculares como base para la enseñanza}

Los saberes curriculares se constituyen en la base para el desarrollo de la labor docente de las participantes, cuyos argumentos destacan que los conocimientos adquiridos sobre el currículum les permiten enfocar su acción pedagógica. Al respecto, se evidencia que esta valoración se sitúa desde dos planos; por una parte, una significación del currículum asociada a un dominio técnico cuyo énfasis central es la planificación didáctica; por otra parte, una comprensión vinculada al ejercicio de la práctica docente en su globalidad, como se puede apreciar en las siguientes citas:

La verdad es que es súper importante manejar teoría y porque los niños merecen tú teoría y no podemos salir improvisando, mi experiencia educativa, mis reuniones y todo lo que tiene que ver con el niño debe ser muy respetuoso, no por lo que me han enseñado 
ahora que tiene sus derechos, sino que es demasiado frágil y nosotros podemos marcar a un niño, no solo dejar huellas de amor sino marcarlo para el resto de su vida si no se maneja una teoría. (E2)

En el fondo lo curricular te da un enfoque sobre cómo abordar al niño, porque ahí tu entiendes y te da la organización para todo en el fondo, para planificar, para preparar el ambiente, para todo en realidad, así que es netamente necesario conocer la teoría curricular. (E7)

A pesar de la alta valoración que se le atribuye al domino de la teoría curricular para el abordaje de la labor pedagógica con infantes, llama la atención que cuando se indaga sobre la perspectiva teórica desde la cual se sitúan para emprender sus decisiones en este ámbito, en su mayoría, las participantes hacen alusión a las bases curriculares, es decir, al marco curricular nacional; inclusive, se refieren metafóricamente a este documento como la "Biblia" que guía su acción. Por lo tanto, este marco se visualiza como un tipo de documento divino que es asumido y seguido sin ningún cuestionamiento. Es así como exponen lo siguiente;

Yo creo que en educación parvularia uno es totalmente integral, uno no deja nada de lado, uno toma todo, somos como los profesores básicos digamos, pero en una versión mejorada, en el sentido de que uno hace todo, claro el profesor básico hace desde el lenguaje, música, tecnología y todo, pero nosotros lo tenemos todo en nuestras Bases Curriculares, entonces nosotros estamos en un nivel curricular tan integral que no podemos dejar ninguna disciplina de lado. (E6)

Yo ocupo las Bases, pero no recuerdo muy bien lo que son los enfoques, pero en el fondo eso, uno planifica con las Bases, esa es nuestra Biblia. (E7)

Para ser honesta no tenía claro lo que eran los enfoques curriculares, pero estuve mirando, sí, pero yo no los conozco, pero hay uno que se llama psicologista...Sí, está el psicologista, el cual a mi más me representa y sirve personalmente porque toma al individuo como centro, más que la entrega de contenidos. (E1)

Lo anterior permite sostener que las significaciones otorgadas por las educadoras al saber curricular se asumen desde una perspectiva funcional (Catalán, 2016), pues su sistema de creencias sobre la teoría curricular se comprende desde un nivel operativo, evidenciable a partir de seguridad argumentativa con la que aluden al marco curricular nacional como la teoría que sustenta su práctica docente, lo que puede ser explicado desde la utilidad que les 
proporciona este marco para el diseño de sus planificaciones didácticas. Por consiguiente, sus comprensiones sobre la teoría y enfoque curricular quedan restringidas a este documento, por lo que asumen una perspectiva técnica del currículum (Valdés y Turra, 2017). A su vez, llama la atención que una participante declara abiertamente no tener conocimiento sobre los enfoques curriculares para la educación infantil, pero relata que en un momento leyó sobre el enfoque psicologista y destaca que esta perspectiva le hizo sentido porque se centra en el sujeto que aprende. Sin embargo, al indagar más profundamente sobre cómo este enfoque curricular estaría presente en su práctica pedagógica, su respuesta se concentra en el rol activo de infantes y el respeto a su individualidad, pero no proporciona mayores antecedentes teóricos que puedan ser vinculados con su práctica. Este relato experiencial se puede apreciar en la siguiente cita:

yo creo que en cada experiencia que hacemos o que yo por lo menos hago, lo tomo en cuenta porque sin poner un piso como para todos igual, ni una meta para todos igual, si no que cada uno dé lo más que se pueda dar dentro de esa experiencia que se está dando en el aula, considerando sus diferencias, las diferencias propias, cada uno daba lo que podía dar obviamente se estimula a dar más pero no pidiéndole a todos la misma respuesta considerando sus diferencias. (E1)

Por consiguiente, en las comprensiones de las educadoras sobre sus saberes curriculares se advierte la ausencia de conocimientos sobre teoría curricular que actúe como marco referencial para fundamental sus decisiones y acciones pedagógicas en este ámbito, más allá del documento curricular nacional.

\subsubsection{Saberes didácticos que sustentan las prácticas de enseñanza}

Los saberes didácticos son situados desde una dimensión exclusivamente práctica, pues la didáctica es conceptualizada por las educadoras como el conjunto de estrategias y acciones que implementan para favorecer que la población de infantes logre los objetivos de aprendizaje. Si bien, sus comprensiones aluden al cómo enseñan, se evidencia que para ellas adoptan un fin teleológico porque las restringen a las acciones que les permiten favorecer los resultados que son demandados por el marco curricular nacional. Al respecto, las participantes señalan lo siguiente; 
Las estrategias didácticas para mí tienen que ver con las acciones que uno realiza, bueno previamente meditadas, las acciones que uno realiza para favorecer el objetivo de aprendizaje. (E6)

Me imagino que son como las herramientas o las orientaciones que uno ocupa para lograr los aprendizajes y las experiencias, todo lo que lleva al niño finalmente lograr los objetivos propuestos cautelando el currículum que uno se plantea en el establecimiento educacional, el que uno trabaja para el logro de esos aprendizajes esperados. (E1)

Desde el punto de vista operativo, en sus discursos hacen alusión al empleo de estrategias tales como: la promoción del juego, actividades lúdicas, manipulación de material concreto, artes, exploración del entorno, expresión de emociones, movimiento, baile y entonación, por cuanto lo relevante para ellas es que la población de infantes haga cosas por sí mismos, que aprendan haciendo y que sean los protagonistas. Estas estrategias y acciones pueden ser apreciadas en las siguientes citas;

Las estrategias didácticas son el tipo de estrategias que tú utilizas para enseñar, didácticas porque se supone que el niño aprende a través del juego, o sea no se supone, es así, el niño aprende mucho mejor a través del juego por eso habla de didáctica. (E4)

Insisto, todo a través del juego, que sea algo entretenido para ellos y donde ellos sean los protagonistas de sus saberes (E3).

Está el juego, como principal motor el juego es primordial y aquí a través del juego tú enseñas todo, a través del juego el niño aprende a través del juego el niño socializa, se hace más sensible, a través del juego logras todo. (E5)

El arte, la expresión, me gusta mucho que el niño exprese, exprese todo, sus sentimientos, sus emociones, lo hace a través de la pintura, el baile, creando cuentos, en general, la expresión y sobre todo pertinente a su lugar, que nosotros vivimos en una zona rural así que le sacamos bastante provecho a esto, a nuestro medio ambiente. (E3)

En los relatos de las participantes se aprecia una toma de conciencia sobre la relevancia que tiene el juego en el grupo de infantes, al señañar que es su principal actividad de aprendizaje y de socialización. Por tanto, para ella se constituye en la principal estrategia didáctica que implementan en su práctica. Si bien, sus afirmaciones se presentan desde una certeza profesional, están alineadas con lo planteado en la teoría existente sobre el desarrollo 
biopsicosocial y en las políticas promulgadas para la infancia a nivel internacional (Mena et al., 2021) y, al mismo tiempo, responden a lo explicitado en el marco curricular para el nivel educativo, por cuanto se señala que "el juego es, en la Educación Parvularia, un concepto central" (MINEDUC, 2018, p. 32). En este sentido, se puede inferir que sus prácticas vinculadas a la didáctica implícitamente se sostienen desde los aportes teóricos referidos a la relevancia del juego en la educación infantil.

\subsubsection{Saberes evaluativos para el monitoreo de los aprendizajes}

Las educadoras comprenden la evaluación como la acción que les permite registrar y monitorear el aprendizaje de infantes, la que está en estrecha relación con la planificación, porque les permitiría determinar el resultado final derivado de este documento técnicopedagógico;

Evaluación es todo proceso en que uno puede registrar y monitorear el aprendizaje de los niños, más que la evaluación como resultado final es el proceso y aquí es el proceso de monitorear lo que el niño va aprendiendo. (E6)

La evaluación es como el proceso final de la planificación, bueno no final porque se retroalimenta, no puede ir uno sin los otros, porque en la evaluación uno en el fondo ve, cuáles son los objetivos que se cumplieron, los que no y a partir de eso uno vuelve a planificar, es un proceso así, como, no sé cómo decirlo, se retroalimentan juntos. (E7)

Por lo tanto, se desprende que las participantes se sitúan desde una dimensión técnica en lo que respecta a sus comprensiones sobre la evaluación, pues sus discursos se centran fundamentalmente en el empleo de instrumentos para evaluar los aprendizajes de infantes. Solo una de ellas alude a que lleva a cabo una evaluación bajo un enfoque teórico constructivista, no obstante, sus argumentos se centran también en los instrumentos de evaluación que emplea, vale decir, en la dimensión operativa de la evaluación. A su vez, se puede observar que algunas participantes reconocen que al momento de evaluar los aprendizajes de la niñez, sus juicios valorativos emergen desde la intuición con base en ciertos factores contextuales y acciones implementadas que podrían estar condicionando los resultados de aprendizaje. Es así como señalan lo siguiente;

Mis evaluaciones son intuitivas en realidad, trato de ir un poco más allá de lo que dice el aprendizaje que uno espera digamos, porque depende de tantas cosas que el niño no lo logre ya que el niño es un ser tan lleno de situaciones que a lo mejor en algún momento 
no lo logró porque le dio pena y se acordó de la mamá entonces yo lo hago bastante intuitivo, bastante amplio y flexible. (E1)

El proceso de ver la manera en el que el niño está aprendiendo y no solamente el niño porque a veces uno teóricamente dice que evalúa al niño, pero a veces uno también se evalúa sí mismo, sus propias prácticas para ver si lo que yo estoy haciendo está de acuerdo a lo que el niño puede realizar, (E6)

Evaluamos con escala de apreciación, logrado, medianamente logrado y por lograr, además como que hacemos una evaluación cualitativa. (E7)

En lo que respecta a sus prácticas evaluativas, se evidencia que estas quedan restringidas al empleo de instrumentos de evaluación que son propios del nivel educativo tales como: la hoja de cotejo y registro el anecdótico. En función de quienes evalúan, también se hace alusión al empleo de la autoevaluación, por cuanto se valora como una oportunidad de aprendizaje para el niño o la niña, la que es intencionada con el propósito de promover la capacidad de autocrítica y la motivación por superar sus propios resultados. Llama la atención que una de las participantes declara utilizar pruebas estandarizadas para monitorear el aprendizaje de los y las infantes a mediados del año, cuya justificación simplemente se corresponde con dar respuesta a una práctica instalada en el establecimiento, pues debe ser aplicada a todos los cursos. Las siguientes citas permiten apreciar los relatos de las participantes;

Utilizo el registro anecdótico y lista de cotejo, lo más que me gusta utilizar es el registro anecdótico, más que si lo logro o no lo logró, te lleva a finalmente a tener como una idea más... donde puedes ir aportando más cosas, registro hoy día, registro mañana no solamente un si lo logró o un no lo logró o medianamente logrado se utilizan todos los instrumentos dependiendo la experiencia claramente. (E1)

Nosotros en el colegio todos los años hacemos una evaluación que de rigor es una evaluación escrita, que se le hace a todos los estudiantes de prekínder hasta cuarto medio que es para saber cómo van los contenidos a esta altura, una prueba estandarizada, cada docente elabora las de su nivel para corresponder a los aprendizajes que están trabajando, se realiza a mitad de año. (E5)

Una experiencia es que los niños se autoevaluaron y a través de esa autoevaluación uno logra ver más allá también, porque a veces los niños no logran las cosas por timidez, 
porque a lo mejor se vino con pena y a través de la autoevaluación yo logré descubrir un montón de cosas. (E1)

Se desprende así que para las participantes, la evaluación adopta una alta relevancia dentro de su labor profesional porque les permitiría monitorear el aprendizaje del párvulo. Sin embargo, sus comprensiones sobre la evaluación se reducen al registro de instrumentos evaluativos como acciones centrales implementadas para determinar los resultados en los aprendizajes. Si bien, los instrumentos que ellas señalan emplear son pertinentes para este nivel educativo porque permiten realizar registros cualitativos sobre el desempeño de los niños y niñas (Espinoza, 2016), las participantes prescinden de antecedentes sobre el enfoque teórico desde dónde se sitúan para abordar sus prácticas evaluativas. Esta omisión resulta ser llamativa, porque en el marco curricular chileno se explicita como perspectiva la "evaluación auténtica" (MINEDUC, 2018, p.103) y, de acuerdo a lo señalado por ellas, este marco representa metafóricamente la "Biblia".

\subsubsection{Saberes sobre las teorías de aprendizaje que orientan la enseñanza}

Las educadoras mayormente se refieren al constructivismo como teoría del aprendizaje que sustenta su labor pedagógica, y argumentan que los niños y niñas son capaces de construir sus propios aprendizajes a través de las experiencias en las que aprenden haciendo. Se destaca que una educadora manifiesta sustentar su enseñanza a partir de un ensamblaje teórico, argumentando que el objetivo es que la población de infantes aprenda, pero no proporciona mayores antecedentes sobre cuáles son aquellas teorías de las que extrae ciertos aspectos que le permiten sustentar su práctica de enseñanza para promover aprendizajes, lo que puede ser apreciado en las siguientes citas que se exponen a modo de ejemplo de sus relatos;

Ellos son creadores de su propio aprendizaje y además ellos así afianzan los aprendizajes, no se les olvidan, son parte de ellos. (E3)

Puede ser de la cognitiva o la constructivista de la que más sacamos, porque la constructivista nos va ayudando en el hacer día a día, en el aprender haciendo, construyendo y la cognitiva porque obviamente estamos tratando de que ellas aprendan a hacerlo por sí mismas, de que ellas piensen el por qué, por ejemplo. (E5)

En la práctica no es que tu tomes en cuenta una teoría para poder aplicar algo, cuando tú piensas en enseñar algo tomas un poco de todas, porque tu objetivo es que aprenda, 
ahora cómo lo aprenda va a variar del niño, va a depender del niño, todos aprenden de forma distinta, o siempre por lo menos dentro del grupo hay uno que aprende de una forma distinta, entonces, así como una teoría, la verdad es que yo no tomo como ninguna. (E4)

En sus discursos, las educadoras hacen alusión mayormente el constructivismo como enfoque teórico bajo el cual comprenden el proceso de aprendizaje de los niños y niñas, lo que está en la línea de resultados encontrados por lbáñez (2014), pero se evidencia que sus comprensiones se construyen desde lo que ellas creen que resulta ser la teoría o teorías del aprendizaje que le dan respaldo su labor, y no desde certezas epistémicas.

\subsection{Saberes pedagógicos y experienciales adquiridos sobre la enseñanza}

La mayoría de las participantes comprende que el saber pedagógico se va nutriendo desde la experiencia y que es entendido como el conjunto de conocimientos que necesitan para desarrollarse en su vida laboral. Señalan, además, que este saber se corresponde con todos aquellos conocimientos adquiridos desde su formación inicial hasta su desarrollo profesional. Por lo tanto, a partir de sus compresiones se desprende que este saber está integrado por un dominio teórico correspondiente a contenidos disciplinares impartidos por la universidad, por sus conocimientos experienciales y por sus características personales. En concreto, para las educadoras este saber refleja todo aquello que saben, que saben enseñar, que las define como profesionales y como personas. Al respecto, señalan lo siguiente;

Mis saberes pedagógicos es lo que en sí soy como educadora de infantes, lo que me enseñó la Universidad, lo que me enseñó la formalidad, en cursos de perfeccionamiento más todo lo que yo he adquirido en el transcurso de mi vida, lo que es informal también, lo que aprendo haciendo a través de mis prácticas pedagógicas. (E2)

Para mí el saber pedagógico no solo se aplica a los conocimientos teóricos que podríamos manejar, sino que yo creo que es una gama amplia de saberes, entre comillas, desde lo que nosotros traemos desde una formación de familia, por ejemplo, desde lo que vamos adquiriendo a través de nuestro crecimiento, aparte del que nos entrega a la universidad y la práctica en sí. (E5)

Dentro de los saberes experienciales que han adquirido se destacan convicciones asociadas a que la niñez aprende a través de material concreto, por medio de experiencias 
desafiantes que les invite a resolver problemas de la vida cotidiana a través del trabajo colaborativo con pares y la repetición de ciertas acciones. A su vez, algunas de ellas enfatizan sobre la importancia que tiene el juego dentro del proceso de aprendizaje en la infancia, porque por medio de esta actividad la persona descubre, indaga, socializa, comparte y desarrolla muchas de sus habilidades sociales y motoras, al transformarse de este modo en la principal estrategia didáctica que señalan implementar. Es así como exponen lo siguiente;

Con el hacer, con experimentar fundamentalmente más que con el conocer, aunque con el conocer también, nuestros niños saben mucho, son niños que están frente a pantalla, conectados a Internet, tienen mucha más información por eso que la experiencia es mucho más valedera cuando hay un hacer más que un conocer. (E1)

Me he dado cuenta de que las niñas aprenden haciendo, escuchando, observando, no todos aprenden igual, por eso una actividad debe repetirse de muchas formas, por ejemplo, un cuento, trabajar de muchas formas, un día podemos actuarlo, otro día podemos dibujar la parte favorita del cuento, podemos reconocer las emociones de los personajes del cuento, siento que una habilidad debe trabajarse muchas veces y de diferentes formas para que puedan ser logradas. (E5)

Nos hemos dado cuenta de que aprenden mucho en el juego. Nosotras observamos muchas conductas, que observamos en el juego, cuando ellos están en el patio jugando, cuando los vemos en otros contextos que no sea el de aula, en el juego los niños como que se muestran tal como son. (E7)

Como parte de los saberes experienciales, también se observa la relevancia atribuida a la emocionalidad de los niños y niñas, pues las participantes destacan que se transforma en un ámbito fundamental para el aprendizaje de los contenidos que quieren transmitir, donde el vínculo afectivo que logran establecer con ellos y ellas les permite favorecer el desarrollo integral. Estos saberes pueden ser evidenciados en los siguientes fragmentos;

Hacerlo tan emocional, en una experiencia incluir más... currículum o... esto tiene un nombre, hacerlo más integral con esa clase de matemática, hice una cosa maravillosa sin usar una guía, bueno te lo digo, porque todo el mundo está usando guías... guías, pero los párvulos no necesitan eso, lo contrario y yo en una video llamada trabaje 4 áreas, te fijas. (E2) 
Yo personalmente trabajo harto el tema de las emociones porque creo que va mucho de la mano con lo otro, y creo que es esencial para poder llevar a cabo lo otro. No puede haber contenido sin esa educación emocional. (E6)

El saber pedagógico es representado por las educadoras como el complemento entre aquellos conocimientos formales enseñados en su formación docente (inicial y continua) y aquellos aprendidos a lo largo de su experiencia profesional, los que, en su conjunto, las define como profesionales y les permite fundamentar su práctica (Sánchez-Amaya y González-Melo (2016). Si bien, en el ejercicio de su labor docente han llegado a elaborar certezas sobre aquellos aspectos que deben ser priorizados en la educación infantil, entre ellas, la promoción del juego y el desarrollo emocional del grupo de infantes, en sus relatos se aprecia que estas convicciones derivan de la implementación de experiencias de aprendizaje percibidas como exitosas y al amparo de sus propias creencias. Por esta razón, responderían a saberes que se enmarcan prioritariamente desde una dimensión afectiva (Echeverría, 2010), desde un saber que no tiene su origen en las instituciones de formación docente, sino que emerge en la práctica de la profesión a partir de un proceso asociado a un "darse cuenta de...", donde las decisiones y acciones pedagógicas estarían fundamentadas con base en aquel conocimiento experiencial que se valida individual y colectivamente en la acción (Tardif, 2010).

A pesar de que el saber experiencial es uno de los constitutivos del saber docente y resulta trascendental para la práctica pedagógica, no es el único tipo de saber que debería desplegarse en el ejercicio de la profesión, pues se reconoce la relevancia de los conocimientos teórico-conceptuales como aquellos marcos proposicionales que contribuyen a la conformación de sistemas más o menos coherentes de representación y de orientación de la actividad educativa (Tardif, 2010). En consecuencia, las prácticas docentes de las educadoras, al estar sustentadas solo desde una dimensión emocional y experiencial, permite evidenciar en estas profesionales una "no comprensión cabal de la relación entre la teoría que se aprende y la práctica en situaciones concretas, que es lo que articula los saberes constitutivos del saber pedagógico". (Ibáñez, 2014, p. 154).

\subsection{Reflexión docente como acción para mejorar la enseñanza}

Las educadoras señalan que la reflexión docente les permitiría analizar su desempeño a partir de una toma de conciencia sobre aquello que les da resultado y lo que no dentro de su práctica pedagógica, lo que se vincula con un ejercicio autoevaluativo. Aunque este proceso 
reflexivo lo implementan en forma individual, también destacan la importancia que le atribuyen a las instancias colectivas de reflexión que se generan dentro de los espacios laborales en los que tienen posibilidades de intercambiar experiencias con sus pares, pues, al decir de ellas, estos espacios les permiten aprender de las experiencias que relatan sus colegas y ello les permite tomar decisiones para mejorar su quehacer docente. Al respecto, exponen lo siguiente;

La comprendo como algo súper necesario porque siento que no se puede avanzar y avanzar sin hacer un stop, mirar hacia atrás y ver si está bien hecho o no está bien hecho, ya que hay muchas teorías y cosas nuevas que te dicen esto sí, esto acá, esto allá, hay que hacer una reflexión si sirve o no. (E1)

Es muy importante porque a través de la reflexión docente nos damos cuenta si nuestro trabajo está adecuado o no a las necesidades de los niños, a sus necesidades educativas, también nos permite ver nuestros propios errores, porque nosotros a veces planificamos y pensamos que es algo que nos va a dar resultado y no es así y la reflexión docente con otros colegas nos permite también mejorar, perfeccionar nuestras propias prácticas, porque los saberes de otros colegas también nos sirven a nosotros y el mío en este caso también les sirve a mis colegas. (E3)

En cuanto a los momentos en que señalan reflexionar, se aprecia que estos tienen lugar en diferentes instancias y son desarrollados de diversas formas. Es así como destacan que emprenden acciones reflexivas sobre su práctica una vez que han terminado de desarrollar alguna experiencia de aprendizaje y/o al finalizar la jornada. En cuanto a la reflexión colectiva, esta tendría lugar mayoritariamente en reuniones formales establecidas dentro de la jornada laboral, como se puede evidenciar en las siguientes citas;

Reflexiono cada día, me cuestiono cómo me entregué, cómo fue la jornada, cómo estuvieron los niños y también la reflexión pedagógica me la dan los resultados con los niños, o sea si los niños se van contentos y su carita feliz, siempre estoy reflexionando que por ahí va la cosa, por ahí es el camino, yo creo que me lo cuestiono siempre la verdad. (E1)

Tenemos una reunión con mi equipo de trabajo, donde todos los lunes o cuando se puede, pero lo importante es que nos juntamos y vamos viendo temas que son importantes, que son contingentes temas de curso también intercambiamos ideas, es como súper rico el trabajo en equipo que tenemos, como que nos complementamos y no solo con nuestra colega de aula sino que con las otras colegas también nos 
ayudamos, por ejemplo, lo que a una le sirve a otra lo puede implementar o al revés, lo que no le sirvió a la otra ya lo va a tener pendiente para no hacerlo, cosas así, no lo hacemos formalmente pero de alguna forma lo llevamos a cabo. (E7)

Respecto de las acciones de mejoramiento que emergen a partir de los procesos reflexivos, se observa una toma de conciencia a nivel colectivo sobre la necesidad de romper con prácticas de enseñanza escolarizantes. Al respecto, reconocen que este tipo de formas de enseñanza demandan una sobreexigencia madurativa a infantes, y cuyo análisis las llevó a cambiar de estrategia. Del mismo modo, señalan que los procesos reflexivos les han permitido objetivar sus prácticas docentes y con ello mejorar, por ejemplo, la calidad de los tiempos de aprendizaje, la calidad de los materiales que ponen a su disposición y la promoción del juego como actividad natural. A pesar de hacer alusión a algunas experiencias en las que la reflexión les ha ayudado a mejorar sus prácticas docentes, también reconocen que implementar cambios no es un proceso fácil porque implica romper con estructuras que están instaladas en las escuelas, lo que puede ser apreciado en los siguientes relatos;

En esa reflexión empezamos a darnos cuenta de que a todos nos pasa lo mismo entonces le estábamos enseñando a los niños a escribir bajo un sistema de presión atroz, lloraban porque no lograban la parte de la escritura, entonces nosotros dijimos...este año vamos a hacer un quiebre, entonces primero vamos a empezar a trabajar habilidades básicas manuales, a trabajar con los deditos, a picar papel con las manos, con actividades de artes y fue un mundo de diferencia, nos evitamos bastantes llantos y problemas que teníamos antes porque entendimos que su proceso no era el que estábamos llevando, entonces no era una habilidad que estaba lista aún en su proceso de desarrollo, esa fue el momento en que la reflexión pedagógica nos ayudó mucho. (E5)

La reflexión docente tiene que ir, porque es la única forma de poder saber si lo estoy haciendo bien o mal, la reflexión pedagógica me hace conversar con otros y con otros aprender, compartir hasta la enseñanza de otras personas. (E2)

Yo creo que la reflexión docente es el mirar tu trabajo, yo creo que es el mirarte a ti misma, el analizar si lo estoy haciendo bien, si no lo estoy haciendo bien, por qué no lo estoy haciendo tan bien, que tengo que mejorar, es cómo eso, pero eso va como muy de la mano yo creo también y siempre he peleado por eso, por una mirada externa. (E4) 
Para las educadoras, los procesos reflexivos que logran implementar en espacios y tiempos formalmente definidos dentro de su jornada laboral son altamente relevantes, porque las interacciones e intercambios de experiencias que allí se generan les han permitido analizar sus prácticas docentes y tomar decisiones focalizadas en el mejoramiento de sus estrategias didácticas para hacerlas más pertinentes a la etapa madurativa de los niños y niñas. Sin embargo, este proceso reflexivo responde a deliberaciones sostenidas fundamentalmente desde un dominio experiencial en función de resultados, situándose así desde una dimensión técnica (Molina, 2008), pero no logran avanzar hacia un análisis profundo que les permita observar sus actuaciones profesionales a partir de procesos reflexivos críticos sustentados en marcos referenciales sobre los aportes teóricos específicos vinculados a las perspectivas curriculares, a la didáctica (Violante, 2018; Zabalza, 2017) y a la evaluación dentro de la pedagogía infantil.

Por consiguiente, las acciones reflexivas que implementan las educadoras se sitúan desde un nivel descriptivo y sus prácticas de enseñanza son analizadas en función de la valoración percibida de acuerdo con las respuestas de los niños y niñas, situación que permite señalar que aquellas experiencias que son socializadas en los espacios de reflexión colectiva se transforman en sus marcos referenciales, pero estas experiencias compartidas escasamente son objeto de una lectura crítica sostenida con base en el contraste dialéctico con la teoría, lo que impide que sus saberes pedagógicos tengan un componente formativo para ellas (Ripamonti, Lizana y Yori, 2016).

\section{Conclusiones}

El saber pedagógico corresponde a un tipo de saber práctico y experiencial inherente a la acción docente que se va configurando en el devenir del ejercicio profesional a la base de procesos reflexivos en y sobre la práctica de enseñanza, pero sustentados en la generación de relaciones dialécticas entre la teoría y la práctica. En base a esta postura, los resultados del estudio permiten concluir que estos saberes para las educadoras poseen un importante significado porque reflejan su "ser" como profesionales y, derivado de ello, le atribuyen una positiva valoración expresada en las convicciones y certezas que han ido construyendo en torno a la enseñanza que implementan para favorecer aprendizajes en los y las infantes.

La significación atribuida por las participantes a su saber enseñar permite visualizar que sus decisiones pedagógicas emergen en forma intuitiva, fundamentalmente desde la experiencia y legitimadas desde una dimensión emocional. Si bien, esta forma en la que 
emerge el saber pedagógico en las educadoras pareciera ser plausible, se concluye que este saber, al situarse solo desde un nivel experiencial, no logra avanzar hacia un saber pedagógico, lo que se relaciona estrechamente con los procesos reflexivos que señalan implementar, pues estos son de carácter descriptivos y autorreferenciales. Esta situación evidencia que las deliberaciones individuales y colectivas se focalizan en aquello que les da resultado y, por tanto, aquellas experiencias valoradas como exitosas se transforman en sus marcos de referencia para el mejoramiento de su práctica. En consecuencia, las acciones pedagógicas que implementan estas profesionales reflejan la ausencia de una base epistémica consciente y consistente que les conduzca a significar el proceso educativo y formativo de los niños y niñas, sustentado en un contraste dialéctico de la teoría con su práctica, pues los procesos reflexivos que desarrollan se cristalizan en un nivel técnico, lo que les impide avanzar en la construcción de sus saberes pedagógicos más allá de sus propias creencias y convicciones personales.

Sumado a lo anterior, se concluye que las significaciones otorgadas por estas profesionales a su saber pedagógico, al situarse básicamente desde sus experiencias, intuiciones y creencias, dejan al descubierto los límites del modelo tradicional - asignaturista y aplicacionista - instaurado en su formación inicial, pues estas profesionales han ido construyendo y validando su saber enseñar solo desde la práctica, invisibilizando el conocimiento teórico que les fue transferido en su paso por la universidad. Por consiguiente, uno de los desafíos que continúan presentando los planes de estudio vinculados a la pedagogía infantil está en la línea de resignificar el modelo tradicional o positivista bajo el cual son concebidos, diseñados y desarrollados, pues, como se pudo apreciar, la teoría transmitida por la institución formadora escasamente logra trascender hacia el ejercicio de la profesión, por lo que se transforma en una falsa representación de los saberes profesionales con respecto a la práctica pedagógica.(Tardif, 2010). Como una forma de revertir esta situación, se insiste sobre la necesidad de implementar en la formación inicial estrategias que permitan generar espacios de encuentro entre los conocimientos teóricos que son entregados en la universidad con aquellos saberes prácticos que son elaborados y reelaborados en el espacio escolar, pero bajo la comprensión de que ambos tipos de saberes, aunque emergen desde concepciones epistemológicas y realidades contextuales distintas, requieren ser complementados a lo largo de la formación inicial y del ejercicio profesional.

Si bien, los procesos formativos del profesorado han estado históricamente permeados por la disociación entre la teoría y la práctica, hoy en día el gran desafío está en avanzar hacia 
modelos epistemológicos integradores, donde la teoría y la práctica se conciban como ámbitos de conocimientos unificados y mutuamente dependientes, vinculados a partir de la promoción de procesos reflexivos críticos que contribuyan a la construcción de aquellos saberes pedagógicos necesarios para que personas educadoras de infantes puedan respaldar sólidamente sus decisiones profesionales y acciones docentes en función de contribuir a la calidad de la educación infantil y de resguardar su sentido.

A pesar de que en la actualidad ha habido un aumento importante de investigaciones que se han focalizado en los saberes del personal docente como objeto de estudio, se sugiere continuar indagando en la construcción del saber pedagógico de profesionales que se desempeñan en la educación infantil, pues el cuerpo de conocimientos científicos en este nivel educativo es aún insipiente. En términos operativos, se sugiere, por ejemplo, el desarrollo de estudios que se centren en la valoración que le otorga el estudiantado de la carrera de Pedagogía en Educación Parvularia a las estrategias que se emplean en las distintas asignaturas del plan de estudio para promover procesos reflexivos críticos, bajo el entendido que la reflexión docente se constituye en una acción formativa trascendental que debe ser intencionada desde la formación inicial, por cuanto puede actuar como la plataforma que permite enlazar dialécticamente la teoría y la práctica. Fundamentalmente, se recomienda centrar la atención en las asignaturas de práctica o prácticum, porque se constituyen en las instancias formativas propicias para la adquisición de aquel saber pedagógico que servirá de base para iniciarse en el ejercicio profesional.

Finalmente, se puede decir que las limitaciones de este estudio se presentan en las escasas posibilidades contextuales de aplicación de otras técnicas de obtención de información que pudieran ser contrastadas entre sí para otorgarle una mayor consistencia a los resultados obtenidos, pues inicialmente se había considerado la observación directa no participante de las prácticas pedagógicas implementadas con el propósito de obtener una visión más global sobre cómo las educadoras van construyendo su saber pedagógico directamente desde las vivencias áulicas, pero la situación de distanciamiento físico generada por la condición de pandemia al momento de la recogida de datos impidió poder lograr ese acercamiento. Del mismo modo, al emplearse la entrevista como única técnica de producción de información, los resultados pueden presentar sesgos en lo que respecta a las características de las prácticas pedagógicas que implementan las participantes, porque estos se presentan a partir de sus propios relatos, es decir, de lo que ellas dicen que hacen, lo que no necesariamente puede ser el reflejo de lo que ocurre en la cotidianeidad del aula con los y 
las infantes. Finalmente, se puede señalar que el estudio al ser abordado bajo un enfoque cualitativo, por su naturaleza subjetiva, los resultados aquí presentados pueden estar condicionados a sesgos de las personas que conformaron el equipo de investigación.

\section{Agradecimientos}

Este artículo presenta resultados del Proyecto Fondecyt N¹1190477, ANID-Chile, La práctica profesional y su aporte a la construcción de saberes pedagógicos en el futuro profesorado: un estudio desde la triada formativa; y del Proyecto DIUBB GI/VC N¹95723 Grupo de Investigación PROFOP: Profesorado y Políticas de Formación, Universidad del BíoBío, Chile.

\section{Referencias}

Aguilar, Renato., y Tansani, Rubén. (2012). Joint analysis of preschool attendance and school performance in the short and longrun. International Journal of Educational Development, 32(2), 224-231. https://doi.org/10.1016/j.ijedudev.2011.03.001

Altet, Marguerite. (2005). La competencia del maestro profesional o la importancia de saber analizar las prácticas. En Léopold Paquay, Marguerite Altet, Évelyne Charlier y Philippe Perrenoud (Coords), La formación profesional del maestro. Estrategias y competencias. (pp. 33-48). Fondo de Cultura Económica.

Ayala-Carabajo, Raquel. (2018). La relación pedagógica: en las fuentes de la experiencia educativa con van Manen. Revista Complutense de Educación, 29(1), 27-41. http://dx.doi.org/10.5209/RCED.51925

Banco Mundial. (2011). Early Childhood development Policies Around the World. Objectives, Conceptual Framework and Methodological Approach. Banco Mundial.

Beillerot, Jacky. (1998). La formación de formadores entre la teoría y la práctica. Buenos Aires: Novedades Educativas.

Belsky, Jay. (2005). Child Care and Its Impact on Young Children (0-2). En Encyclopedia of Early Childhood Development. https://www.childencyclopedia.com/sites/default/files/textes-experts/en/857/child-care-and-its-impact-onyoung-children.pdf

Bisquerra, Rafael. (2004). Metodología de la Investigación Educativa. La Muralla.

Bravo, Astrid., y Morales, Hernán. (2012). Caracterización de educadoras de párvulos que se desempeñan en el nivel sala cuna en una muestra de jardines infantiles de Concepción, Chile. Revista Electrónica Actualidades Investigativas en Educación, 12(2), 1-25. http://www.redalyc.org/pdf/447/44723437009.pdf 
Catalán, Jorge. (2016). Hacia la formulación de una teoría general de las teorías subjetivas. Psicoperspectivas, 15(1), 53-65. 10.5027/psicoperspectivas-Vol15-Issue1-fulltext-739

Charlot, Bernard. (2010). La relación con el saber. Elementos para una teoría. Buenos Aires: El Zorzal.

Contreras, José. (2011). El lugar de la experiencia. Cuadernos de Pedagogía, (417), 60-63. https://www.researchgate.net/publication/335224252 El lugar de la experiencia

Cortázar, Alejandra., y Vielma, Constanza. (2017). Educación parvularia chilena: Efectos por género y años de participación. Revista Calidad en la Educación, (47), 19-42. https://scielo.conicyt.cl/pdf/caledu/n47/0718-4565-caledu-47-00019.pdf

Cortés Véliz, Johanna. (2014). Reflexión pedagógica de las educadoras de párvulos: racionalidades y contenidos. Temas de Educación, 20(1), 67-82. https://revistas.userena.cl/index.php/teduacion/article/view/520

Echeverría, Priscila. (2010). El papel de la docencia universitaria en la formación inicial de profesores. Revista Calidad en la Educación, (32), 150-165. https://www.calidadenlaeducacion.cl/index.php/rce/article/view/154/160

Espinoza, Paula. (2016). Creencias de las educadoras de educación infantil sobre la evaluación de los aprendizajes. Un estudio de caso de cuatro educadoras de Santiago de Chile (Tesis de Doctorado). Universidad de Barcelona, Barcelona, España. http://diposit.ub.edu/dspace/bitstream/2445/106169/1/PCEL TESIS.pdf

Flick, Uwe. (2012). Introducción a la investigación cualitativa. Ediciones Morata.

Flores-Lueg, Carolina., Gajardo-Rodríguez, Ana., y Navarrete-Troncoso, Lucía. (2016). Significado atribuido por Educadoras de Párvulos a los contextos para el aprendizaje en $\begin{array}{llll}\text { el nivel de sala cuna. IEYA, 2(1), } & 115-137 .\end{array}$ https://revistas.uv.cl/index.php/IEYA/article/view/587/581

Herrera, José Darío., y Martínez, Ángela. (2018). El saber pedagógico como saber práctico. Pedagogía y Saberes, (49), 9-26. http://www.scielo.org.co/pdf/ppo/n19/2011-804X-ppo19-00009.pdf

Hizmeri, Julio., Contreras, Gladys., Aparicio, Carolina., Otondo, Maite., y Espinoza, Javier. (2020). Experiencias y saberes pedagógicos de docentes en el comienzo del oficio educativo: una indagación narrativa. Revista Brasileira de Educação, 25, e250053. https://doi.org/10.1590/s1413-24782020250053

Ibáñez, Nolfa. (2014). Saberes profesionales para la transformación del modelo educativo en Chile. Estudios Pedagógicos, 40(Especial), 145-160. https://scielo.conicyt.cl/pdf/estped/v40nEspecial/art09.pdf

Kvale, Steinar. (2011). Las entrevistas en Investigación Cualitativa. Ediciones Morata. 
Lería, Francisco., Salgado, Jorge., y Sasso, Patricia. (2018). Sentido Subjetivo de Educadoras de Párvulos en el uso e impacto del silencio en el aprendizaje. Revista Iberoamericana sobre Calidad, Eficacia y Cambio en Educación, 16(2), 77-97. https://revistas.uam.es/index.php/reice/article/view/9425

Mena Bastías, Carmen., Flores Lueg, Carolina., Arteaga González, Patricia., Saldaña Espinoza, Dalys., y Navarrete Troncoso, Lucía. (2021). Juego en primera infancia. Aproximación al significado otorgado por educadoras de párvulos. Cuadernos de Investigación Educativa, 12(1). https://doi.org/10.18861/cied.2021.12.1.3063

Mercado, Ruth. (2018). Los saberes docentes como construcción social: la enseñanza centrada en los niños. Fondo de Cultura Económica

Merellano-Navarro, Eugenio., Almonacid-Fierro, Alejandro., y Muñoz-Oyarce, Ma . Francisca. (2019). Resignificando el saber pedagógico: una mirada desde la práctica docente. Educ. Pesqui., São Paulo, 45, e192146,1-18. https://www.scielo.br/pdf/ep/v45/1517-9702-ep45-e192146.pdf

Messina, Graciela. (2008). Formación docente: del control al saber pedagógico. Revista Docencia, Colegio de Profesores de Chile, (34), 78-86. https://www.yumpu.com/es/document/read/36453469/leer-articulo-completo-revista$\underline{\text { docencia }}$

Ministerio de Educación (MINEDUC). (2018). Bases Curriculares Educación Parvularia. Subsecretaría de Educación Parvularia. https://parvularia.mineduc.cl/wpcontent/uploads/sites/34/2018/03/Bases Curriculares Ed Parvularia 2018.pdf

Molina, Pilar. (2008). Práctica docente progresiva en la formación inicial desde un enfoque reflexivo crítico. En José Cornejo y Rodrigo Fuentealba (Eds.), Prácticas reflexivas para la formación profesional docente: ¿qué las hace eficaces?, (pp. 13-27). Ediciones UCSH.

Morales, Soledad., Quilaqueo, Daniel., y Uribe, Pilar. (2010). Saber pedagógico y disciplinario del educador de infancia: Un estudio en el sur de Chile. Perfiles educativos, 32(130), 4966. http://www.scielo.org.mx/scielo.php?script=sci arttext\&pid=S0185$26982010000400004 \&$ lng=es\&tlng=es

Moreno Vera, Fabiola y de la Herrán Gascón, Agustín. (2017). Conocimientos disciplinares y pedagógicos de las Educadoras de Párvulos en Chile. Profesorado. Revista de

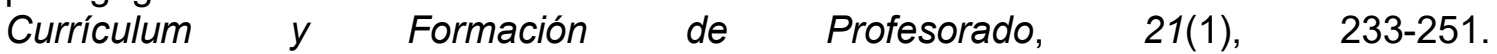
https://recyt.fecyt.es/index.php/profesorado/article/view/58061

Pedemonte, Fabián. (2009). Desarrollo del profesorado: el saber pedagógico y la tradición del profesor como profesional reflexivo. Acción Pedagógica, 18(1), 42-51. https://dialnet.unirioja.es/servlet/articulo?codigo=3122365

Porta, María José., y Cometta, Ana Lía. (2017). Acerca de los saberes docentes: enfoques y aportes teóricos. entreVistas [Revista de Debates], 7(9), 1-10. http://www.isnsc.com.ar/Revista/edicion 009/ porta-cometta.pdf 
Ramírez-Abraham, Patricia; Patiño-Mora, Vivian y Gamboa-Vásquez, Elsa. (2014). La educación temprana para niños y niñas desde nacimiento a los 3 años: Tres perspectivas de análisis. Revista Electrónica Educare (Educare Electronic Journal), 18(3), 67-90. http://dx.doi.org/10.15359/ree.18-3.5

Ripamonti, Paula., Lizana, Patricia., y Yori, Patricia. (2016). La construcción de los saberes prácticos docentes. Una mirada desde narraciones biográficas y pedagógicas. Saberes y prácticas. Revista de Filosofía y Educación, 1, 1-23. http://revistas.uncu.edu.ar/ojs3/index.php/saberesypracticas/article/view/780/489

Rolla, Andrea., Leal, Paola., y Torres, Natalia. (2011). Diagnóstico de la educación parvularia en Chile: Avances y Desafíos. En Felipe Cousiño y Ana María Foxley (Eds.), Políticas Públicas para la Infancia (pp. 17-42). Comisión Nacional Chilena de Cooperación con UNESCO.

http://www.unesco.org/new/fileadmin/MULTIMEDIA/FIELD/Santiago/pdf/politicaspublica s.pdf

Román, Fabián., y Poenitz, Victoria. (2018). La Neurociencia Aplicada a la Educación: aportes, desafíos y oportunidades en América Latina. RELAdEI. Revista Latinoamericana de Educación Infantil, 7(1), 88-93. https://revistas.usc.gal/index.php/reladei/article/view/5272

Ruffinelli, Andrea. (2017). Formación de docentes reflexivos: un enfoque en construcción y disputa. Educação e Pesquisa, 43(1), 97-111. https://doi.org/10.1590/s1517$\underline{9702201701158626}$

Ruiz, José. (2012). Metodología de investigación cualitativa. España: Universidad de Deusto.

Sánchez-Amaya, Tomás., y González-Melo, Hamlet. (2016). Saber pedagógico: fundamento del ejercicio docente. Educación y Educadores, 19(2), 241-253. https://www.redalyc.org/pdf/834/83446681004.pdf

Schön, Donald. (1998). El profesional reflexivo: cómo piensan los profesionales cuando actúan. Barcelona: Paidós.

Suescun Guerrero, Wilberth., y León Salazar, Anibal. (2018). Las fuentes del saber docente, límites y posibilidades en la formación profesional del maestro. EDUCERE, 22(71), $117-$ 129. http://erevistas.saber.ula.ve/index.php/educere/article/view/12083

Tardif, Maurice. (2010). Los saberes del docente y su desarrollo Profesional. Madrid: NARCEA S.A. DE EDICIONES.

Valdés, Mario., y Turra, Omar. (2017). Racionalidades curriculares en la formación del profesorado de historia en Chile. Diálogo andino, (53), 23-32. https://dx.doi.org/10.4067/S0719-26812017000200023

van Manen, Max. (2003). Investigación educativa y experiencia vivida. Ciencia humana para una pedagogía de la acción y sensibilidad. Idea Books, S. A. 
Vezub, Lea. (2016). Los saberes docentes en la formación inicial. La perspectiva de los formadores. Pensamiento Educativo, Revista de Investigación Latinoamericana (PEL), 53(1). https://doi.org/10.7764/PEL.53.1.2016.9

Violante, Rosa. (2018). Didáctica de la Educación Infantil. Reflexiones y Propuestas. Revista Senderos Pedagógicos, (9),

https://ojs.tdea.edu.co/index.php/senderos/article/view/621/770

Zabalza, Miguel Ángel. (2018). Neurociencias y educación infantil. RELAdEl. Revista $\begin{array}{lllll}\text { Latinoamericana De Educación } & \text { Infantil, }\end{array}$ https://revistas.usc.gal/index.php/reladei/article/view/5255

Zabalza, Miguel Ángel. (2017). Didáctica de la Educación Infantil. Narcea Ediciones. 


\section{Anexos}

\section{Guion de Preguntas para entrevista semiestructurada}

\section{Categoría: Saberes profesionales}

\subsection{Sub-categoría: Enfoque curricular}

- ¿Considera necesario que una Educadora de Párvulos tenga conocimientos sobre teoría curricular? y ¿por qué?

- ¿Cómo comprende usted lo qué es el currículum?

- ¿Qué enfoque curricular le da sustento a su práctica pedagógica?

- ¿Podría describir algunas situaciones educativas en las que el enfoque curricular que asume estaría presente?

\subsection{Sub -Categoría: Saberes didácticos}

- ¿Qué entiende usted por didáctica?

- ¿Qué estrategias didácticas utiliza frecuentemente dentro de su quehacer pedagógico?

- ¿Qué estrategias didácticas le resultan más efectivas para lograr los objetivos de aprendizaje?

- ¿Podría narrar una situación donde la aplicación de una estrategia didáctica le haya dado resultado en el aprendizaje de los párvulos?

\subsection{Sub-categoría: Saberes evaluativos}

- ¿Cómo comprende lo que es la evaluación?

- ¿En qué enfoque teórico sustenta sus prácticas evaluativas?

- ¿Qué métodos de evaluación utiliza para monitorear el aprendizaje de los párvulos en el aula?

- Podría describir alguna situación que recuerde sobre sus prácticas de evaluación de los aprendizajes en los párvulos

\subsection{Sub-categoría: Saberes sobre teorías del aprendizaje}

- ¿Qué teoría/as del aprendizaje tiene en cuenta al momento de implementar su labor pedagógica con los párvulos? y ¿por qué?

- ¿Podría describir situaciones educativas en las que usted se haya dado cuenta sobre cómo aprenden los niños y niñas? 


\section{Categoría: Saberes pedagógicos y experienciales}

- ¿Qué entiende usted por saber pedagógico?

- Durante su desarrollo como profesional, ¿qué conocimientos nuevos ha logrado adquirir como educadora y que no fueron entregados en su formación inicial?

- Podría narrar alguna experiencia en la que haya aplicado con los párvulos algún nuevo conocimiento teórico o práctico, y que le haya dado resultado en relación con el logro de aprendizajes

\section{Categoría: Reflexión docente}

- ¿Cómo comprende usted la reflexión docente?

- ¿Considera necesario generar procesos reflexivos sobre su quehacer pedagógico? ¿Por qué?

- ¿Cómo y cuándo reflexiona usted sobre su quehacer docente con los párvulos?

- Podría describir alguna situación puntal en la que haya llevado a cabo un proceso de reflexión que le haya ayudado a mejorar su labor pedagógica con los párvulos 


\section{Revista indizada en}
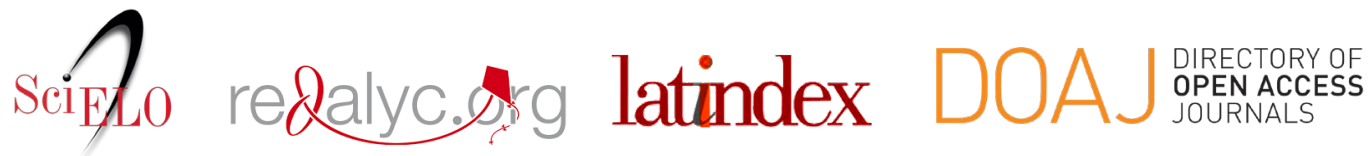

Distribuida en las bases de datos:
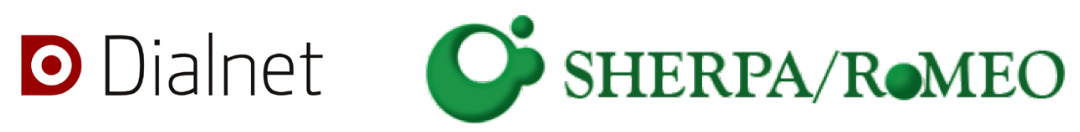

REDIB

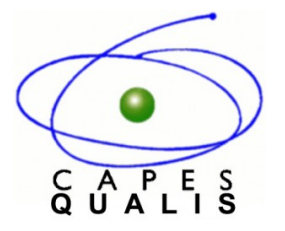

MIAR 